\title{
Karyotype Characterization and Polyploid Variations in Some Genotypes of Triticum aestivum L.
}

\author{
Ehab Abdel-Razik Kamel \\ Department of Biological Sciences and Geology, Faculty of Education, Ain Shams University, \\ P.C.11341 (Heliopolis), Roxy, Cairo, Egypt
}

Received February 13, 2006; accepted March 1, 2006

\begin{abstract}
Summary In this study, karyotype criteria of 14 genotypes of Triticum aestivum L. in addition to one genotype of Triticum durum Desf. are described and polyploid variations are discussed. Detailed karyotype features, i.e. total chromosome length (TCL), mean chromosome length (MCL) and karyotype asymmetry expressed as arm ratio (MAR), total form percent (TF \%), intrachromosomal asymmetry $\left(A_{1}\right)$ and interchromosomal asymmetry $\left(A_{2}\right)$, are also described.
\end{abstract}

Key words Triticum aestivum L., genotypes, karyotype features.

Wheat is one of the most important cereal crops in the world for both human and animals as a food product and source of energy. Bread wheat which includes five species is by far the most useful of the wheats. The most common bread wheat, Triticum aestivum L., may have originated through hybridization between the tetraploid Persian emmer wheat (T. dicoccum) and the goat grass of eastern Turkey and northwestern Iran (Singh 1993).

Polyploidy has played a major role in the speciation of higher plants. In angiosperms, Stebbins $(1950,1971)$ estimated that 30 to $35 \%$ and Grant (1971) suggested that $47 \%$, of species are of polyploid origin and species in which the basic chromosome number is $x=10$ or higher, evolved by polyploidization. In polyploids, $x$ is the basic (monoploid) chromosome number, $n$ is the gametic number of chromosomes and $2 n$ is the zygotic or somatic chromosome number. The genomic formula of Triticum aestivum $\mathrm{L}$. is $2 n=6 x=42$. The basic chromosome number $x$ is 7 . Hexaploid wheat $(2 n=6 x=42)$ is an allopolyploid and contains chromosomes of three genomic diploid of $2 n=2 x=14$ species. Present day T. aestivum wheat is structurally different from originally synthesized tetraploid and hexaploid wheats because of chromosomal changes among the three genomes of wheats (Okamoto and Sears 1962). The species Triticum aestivum which is a hexaploids $(2 n=6 x=42)$ has 6 synonyms, T. compactum, T. n. acha, T. spelta, T. sphaerococcum, T. vaviloi and T. vulgare.

Karyotype analysis has played an important role in the identification and designation of chromosomes in many plant species. Karyotype analysis is usually based on somatic mitotic metaphase chromosomes. Karyotype studies were principally based on the idea that symmetrical karyotypes are more primitive than asymmetrical ones; longer chromosomes than shorter ones; median centromeres with chromosome arms of equal length are more primitive than chromosomes with arms of unequal length; low basic numbers give rise to higher ones. These features are based on the comparison between karyotypes of known relative antiquity, as determined through classical taxonomy (Sharma 1990).

Several studies were carried out on Triticum genotypes dealing with plant breeding programs, plant tissue cultures and genotypic variations (Mohamed 1990, Chowdhury et al. 1991, Ahmed et

\footnotetext{
*Corresponding author, e-mail: ehabk63@yahoo.com
} 
Table 1. Names, source, pedigree and/or selection history of the wheat genotypes used in the study

\begin{tabular}{|c|c|c|c|}
\hline & Genotype & Source & Pedigree and/or selection history \\
\hline 1 & Mexipak 65 & ICARDA & II 8156-OPAK \\
\hline 2 & Sahel-1 & Egypt & Ns. 732/Pima//Veery “S” \#5 Sd735-4Sd-1Sd-1Sd-0Sd \\
\hline 3 & Mar-3 & Egypt* & Cham 4/Sakha 8//2* Sakha 8 Su74-3Mr-32Mr-5Sw-13Sw-0Sw \\
\hline 4 & ID-10 & ICARDA & ICD88-1233-ABL-8AP-0AP-3AP-0AP \\
\hline 5 & Gem-7 & Egypt & CMH74A-630/Xs//Seri82/3/Agent/C Gm4611-2Gm-3Gm-16Gm-0Gm \\
\hline 6 & Giza-168 & Egypt & MRL/BUC//SERI CM93046-8M-0Y-0M-2Y-0B-0GZ \\
\hline 7 & Ma r-5 & Egypt* & Giza 162//Bch'S/4/PI-ICW79 Su5-11Mr-38Mr-1Mr-0Mr \\
\hline 8 & Cham-4 & Syria & CM 39816-1S-1AP-0AP \\
\hline 9 & $\mathrm{~S}_{8} / 17$ & Egypt & $\mathrm{R}_{8}$ tissue culture regenerated double haploid plant \\
\hline 10 & $\mathrm{LR} / 1$ & Egypt & $\mathrm{R}_{8}$ tissue culture regenerated double haploid plant \\
\hline 11 & $\mathrm{LR} / 2$ & Egypt & $\mathrm{R}_{8}$ tissue culture regenerated double haploid plant \\
\hline 12 & Giza-160/1 & Egypt & $\mathrm{R}_{8}$ tissue culture regenerated double haploid plant \\
\hline 13 & Giza-160 & Egypt & L.2188/1131-Chenab 70/Giza 155 \\
\hline 14 & Lerma Rojo-64 & Spain & Long-term check \\
\hline 15 & $\mathrm{LR} / 3$ & Egypt & $\mathrm{R}_{8}$ tissue culture regenerated double haploid plant \\
\hline
\end{tabular}

ICARDA; International Center of Agricultural Research in the Dry Areas.

* Newly bred line released through Desert Research Center, Wheat Breeding Program.

Table 2. The karyological features of the studied genotypes of Triticum aestivum L.

\begin{tabular}{|c|c|c|c|c|c|c|c|c|c|c|c|c|}
\hline \multirow{2}{*}{ Genotype } & \multirow{2}{*}{$x$} & \multirow{2}{*}{$2 n$} & \multirow{2}{*}{$\begin{array}{l}\text { TCL } \\
(\mu \mathrm{m})\end{array}$} & \multirow{2}{*}{$\begin{array}{c}\mathrm{MCL} \pm \mathrm{SE} \\
\quad(\mu \mathrm{m})\end{array}$} & \multirow{2}{*}{$\begin{array}{c}\mathrm{MAR} \pm \mathrm{SE} \\
\text { (r-value) }\end{array}$} & \multirow{2}{*}{$\mathrm{TF} \%$} & \multirow{2}{*}{$\mathrm{A}_{1}$} & \multirow{2}{*}{$\mathrm{A}_{2}$} & \multirow{2}{*}{ SAT } & \multicolumn{3}{|c|}{ Chr. Type } \\
\hline & & & & & & & & & & M & $\mathrm{m}$ & $\mathrm{sm}$ \\
\hline 1 & 7 & 21 & 37.59 & $5.37 \pm 0.30$ & $1.30 \pm 0.07$ & 43.76 & 0.22 & 0.15 & - & - & 7 & - \\
\hline 2 & 7 & 28 & 56.21 & $8.03 \pm 0.81$ & $1.35 \pm 0.13$ & 43.50 & 0.23 & 0.27 & - & - & 6 & 1 \\
\hline 3 & 7 & 28 & 51.40 & $7.34 \pm 0.41$ & $1.42 \pm 0.08$ & 41.67 & 0.29 & 0.15 & + & - & 6 & 1 \\
\hline 4 & 7 & 14 & 45.82 & $6.55 \pm 0.79$ & $1.63 \pm 0.11$ & 38.02 & 0.37 & 0.32 & + & - & 5 & 2 \\
\hline 5 & 7 & 42 & 42.41 & $6.06 \pm 0.51$ & $1.45 \pm 0.06$ & 41.19 & 0.30 & 0.22 & + & - & 7 & - \\
\hline 6 & 7 & 28 & 33.48 & $4.78 \pm 0.35$ & $1.30 \pm 0.07$ & 43.79 & 0.22 & 0.19 & - & 1 & 6 & - \\
\hline 7 & 7 & 42 & 32.38 & $4.63 \pm 0.45$ & $1.28 \pm 0.04$ & 43.45 & 0.22 & 0.26 & - & - & 7 & - \\
\hline 8 & 7 & 42 & 31.65 & $4.52 \pm 0.41$ & $1.23 \pm 0.06$ & 44.49 & 0.18 & 0.24 & - & - & 7 & - \\
\hline 9 & 7 & 42 & 40.44 & $5.78 \pm 0.42$ & $1.32 \pm 0.06$ & 43.18 & 0.23 & 0.19 & - & - & 7 & - \\
\hline 10 & 7 & 28 & 35.02 & $5.00 \pm 0.38$ & $1.33 \pm 0.04$ & 42.89 & 0.24 & 0.20 & - & - & 7 & - \\
\hline 11 & 7 & 28 & 47.95 & $6.85 \pm 0.48$ & $1.24 \pm 0.05$ & 44.75 & 0.18 & 0.18 & + & - & 7 & - \\
\hline 12 & 7 & 42 & 38.53 & $5.50 \pm 0.48$ & $1.48 \pm 0.08$ & 40.85 & 0.31 & 0.23 & + & - & 6 & 1 \\
\hline 13 & 7 & 21 & 38.67 & $5.52 \pm 0.40$ & $1.51 \pm 0.13$ & 40.29 & 0.31 & 0.19 & + & - & 4 & 3 \\
\hline 14 & 7 & 42 & 40.51 & $5.79 \pm 0.43$ & $1.22 \pm 0.04$ & 45.40 & 0.17 & 0.20 & + & - & 7 & - \\
\hline 15 & 7 & 42 & 37.71 & $5.39 \pm 0.52$ & $1.38 \pm 0.08$ & 41.69 & 0.26 & 0.26 & + & - & 7 & - \\
\hline
\end{tabular}

$\mathrm{TCL}=$ Mean Chromosome Length, $\mathrm{MCL}=$ Mean Chromosome Length, MAR $=$ Mean Arm Ratio, SE $=$ Standard Error, $\mathrm{M}=$ Metacentric chromosome, $\mathrm{m}=$ metacentric region chromosome, $\mathrm{sm}=$ submetacentric chromosome, $\mathrm{Chr}$. $=$ Chromosome, $\mathrm{TF} \%=$ Total Form percent, $\mathrm{SAT}=$ Satellite, $\mathrm{A}_{1}=$ Intrachromosomal asymmetry index, $\mathrm{A}_{2}=$ Interchromosomal asymmetry index.

al. 1992, Mohamad 1993, Bahieldin et al. 1994, Barakat and Abdel-Latif 1995, Ozgen et al. 1996, Sesek and Kondic 1997, Rashed et al. 1998, Abdel-Tawab et al. 2002, Rashed et al. 2004).

In the present work, chromosome numbers and detailed karyotype features of 14 genotypes of Triticum aestivum L. in addition to 1 genotype of Triticum durum Desf. were studied.

Materials and methods

\section{Plant materials}

Five $\mathrm{F}_{8}$ double-haploid lines obtained as somaclones via regeneration of plants from callus de- 


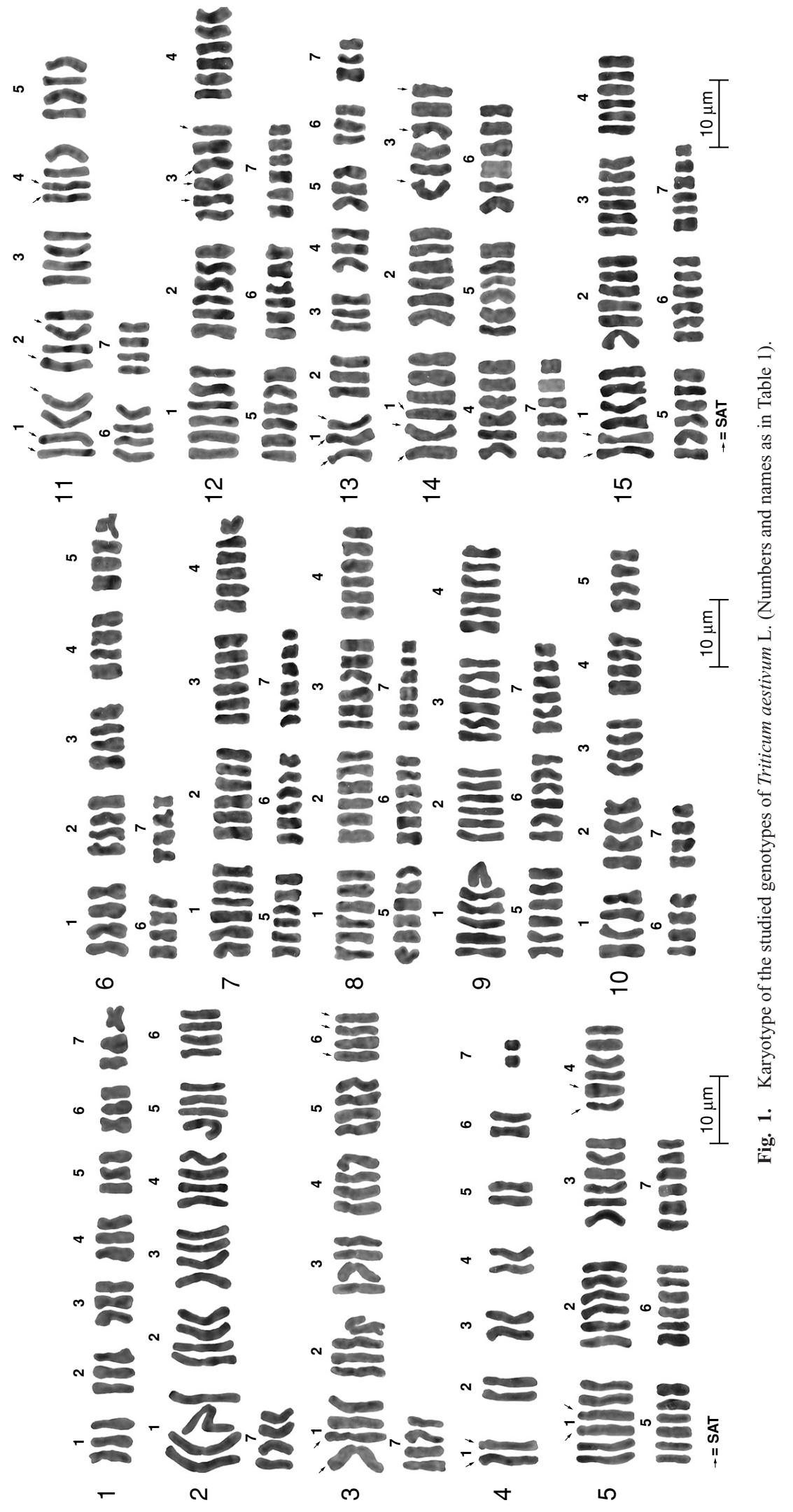


rived from immature inflorescences/embryos of 3 hexaploid bread wheat genotypes; 2 d11887825 ent generations up to $\mathrm{F}_{8}$ derived from a single $\mathrm{R}_{0}$ double-haploid plant through selfed progeny for each line. Such 5 lines which were kindly obtained by Prof. Dr. Kasem Zaki Ahmed, Director of (MCGEB), were compared to 9 bread wheat and 1 durum wheat (ID-10) genotypes. Data of these genotypes illustrated in the following table. The 15 wheat genotypes were grown at Siwa Oasis, Tegzerty Experimental farm of Desert Research Center in 2004/2005 winter season. Soil of the experimental site characterized as sandy loam texture, saline (ECe $\left.12.3 \mathrm{dSm}^{-1}\right)$ calcareous $(18.1 \%$ $\mathrm{CaCO}_{3}$ ) and $0.7 \%$ organic matter. Deep artesian well irrigation water of EC about $4.1 \mathrm{dSm}^{-1}$ was used for supplying nine irrigations through the growing seasons.

\section{Methods}

Cytological preparations were carried out on root tips obtained from seeds germinated on sterile moist filter paper in Petri dishes at $25^{\circ} \mathrm{C}$. Roots were pretreated with $0.05 \%$ colchicine solution for $2-3 \mathrm{~h}$. and fixed in Carnoy for $24 \mathrm{~h}$. and stored in $70 \%$ ethanol at $4{ }^{\circ} \mathrm{C}$. Cytological preparations were made using the Feulgen squash method. The well-spread c-metaphase chromosomes were photographed from temporary preparations at magnifications of $2000 x$. Slides of the original karyotypes are preserved in the Laboratory of Cytogenetics of Biological Sciences and Geology Department, Faculty of Education, Ain Shams University, Roxy, Cairo, Egypt.

A karyogram for each genotype was constructed by arranging the chromosomes in homologous pairs by order of their length and arm ratio as measured from the photographic prints. The number of chromosome types was determined as described by Levan et al. (1965). Measurements of chromosome length were taken on the same photographs of the karyogram.

The variation in chromosome length (MCL) and chromosome arm ratio (MAR) within the karyotype has been estimated by calculating the standard error (SE) of these parameters. Karyotype asymmetry deduced from the ratio between the short arms of the chromosomes and their total length was expressed as total form percent (TF \%) as proposed by Huzwara (1962). Karyotype asymmetry expressed by the ratio between chromosome arms has been also estimated as the intrachromosomal asymmetry index $\left(\mathrm{A}_{1}\right)$ as suggested by Romero-Zarco (1986).

The value of $A_{1}$ is considered to be close to 0 if all chromosomes are metacentric and near to one if all chromosomes are telocentric. Karyotype asymmetry due to the ratio between sizes of different chromosomes has been also estimated as the interchromosomal asymmetry index $\left(\mathrm{A}_{2}\right)$ using Pearson's dispersion coefficient, which is the ratio between the standard deviation and the mean chromosome length (Romero-Zarco 1986).

\section{Results and discussion}

A summary of the karyological features of the studied genotypes of Triticum aestivum L. is given in Table 2 and their karyotypes are illustrated in Figs. 1-3. Among the 15 genotypes studied a somatic chromosome number of $2 n=14$ (a diploid of $x=7$ ) has been found in genotype (4), $2 n=21$ (a triploid of $x=7$ ) in 2 genotypes ( 1 and 13), $2 n=28$ (a tetraploid of $x=7$ ) in 5 genotypes $(2,3,6$, 10 and 11 ) and $2 n=42$ (a hexaploid of $x=7)$ in the rest genotypes $(5,7,8,9,12,14$ and 15).

Total chromosome length (TCL) values vary between genotypes (Table 2). The highest value $(56.21 \mu \mathrm{m})$ is recorded in genotype (2) with mean chromosome length (MCL) of $8.03 \pm 0.81 \mu \mathrm{m}$, while the lowest value $(31.65 \mu \mathrm{m})$ is found in genotype (8) with mean chromosome length (MCL) of $4.52 \pm 0.41 \mu \mathrm{m}$.

The karyotypes of the examined genotypes are considerably symmetric with regard to chromosome length. The most variable chromosomes in length are found in genotype (2) (SE of $\mathrm{MCL}=0.81 \mu \mathrm{m}$ ), whereas the most similar chromosomes are scored in genotype (1) (SE of $\mathrm{MCL}=0.30 \mu \mathrm{m})$. 
All of the genotypes studied have karyotypes of metacentric to submetacentric chromosomes as indicated by their mean $r$-value, whereas the lowest value $(1.22 \pm 0.04)$ is recorded in genotype (14), the highest value $(1.63 \pm 0.11)$ is found in genotype (4). The degree of karyotype asymmetry as indicated by TF\% values ranges between $38.02 \%$ in genotype (4) and $45.40 \%$ in genotype (14). In general, $A_{1}$ and $A_{2}$ values show the high degree of karyotype symmetry in the majority of the genotype studied (Table 2). Eight of the studied genotypes $(3,4,5,11,12,13,14$ and 15) are characterized by the presence of SAT in their chromosome arms (Table 2).

Chromosomal aberrations are common occurrence in cell- and tissue culture-derived calluses and their regenerants. In general, numerical and structural changes in chromosomes are attributed to spindle failure that causes endocreduplication, c-mitosis, nuclear fragmentation, multipolar configurations and lagging chromosomes (Singh 1993). Also, Singh (1986) examined cytologically 10 morphogenic calluses of barley.

On the basis of plant morphology and nuclear genomic constitution, species of the genus Triticum can be groups: einkorn $(2 n=2 x=14)$, emmer $(2 n=4 x=28)$ and dinkel $(2 n=6 x=42)$ (Sears 1975). The emmer and dinkel wheats are allopolyploids. The mode of chromosome pairing in triploid $(2 n=3 x=21)$ and pentaploid $(2 n=5 x=35)$ hybrids helped Kihara (1944) to uncover the ancestral species of allopolyploid wheats.

The morphogenic ability of a callus depends upon the chromosome constitution of the cells. Balanced chromosome numbers in a callus is prerequisite for regeneration plants. This is in agreement with the results reported in Triticum aestivum L. (Ahloowalia 1982). Haploid cells in appreciably low frequency have been recorded in callus cultures of Triticum aestivum L. $(2 n=6 x=42)$ (Novák et al. 1978).

Hexaploid wheat $(2 n=6 x=42)$ is an allohexaploid and contains 3 genomes. Karp and Maddock (1984) studied chromosomes of 192 regenerated plants derived from immature embryo callus of for hexaploid wheat cultivars. A total of $71 \%$ of the regenerants carried the expected $2 n=42$ chromosomes and $29 \%$ of the plants were aneuploid $(2 n=38$ to 45$)$. The most frequently observed numbers were $2 n=41$ to 43 . Chromosome interchanges were recorded; however, no plants with chimaerism, polyploidy or inversion were found.

Generally, by comparing the studied genotypes of Triticum aestivum L. and Triticum durum Desf. obtained from Siwa Oasis, there were great variations in the recorded levels of polyploidy, the total chromosome length and in most of the karyological features. These results are in agreement with previous studies, which carried out on genotypes produced from calluses and their regenerants. Also, great variations were found within the morphological characteristics (i.e. all growth parameters, colour, size of leaves, sizes of cells, stomata, pollens and grains). In Triticum aestivum L. $(2 n=6 x=42)$, plants were found to be larger than their diploid ancestors.

\section{Acknowledgement}

The author is grateful to Prof. Dr. Samy A. N. Afiah, Professor of Genetics and Plant Breeding at Desert Research Center for providing the materials of this study and revising the manuscript.

\section{References}

Abdel-Tawab, F. M., Fahmy, E. M., Bahieldin, A., Mahmoud, A. A., Abdel-Aziz, S. H. and Moseilhy, O. 2002. Genetic improvement of bread wheat (Triticum aestivum L.) for drought tolerance by molecular breeding. Egypt. J. Genet. Cytol. 31: 331-353.

Ahloowalia, B. S. 1982. Plant regeneration from callus culture in wheat. Crop Sci. 22: 405-410.

Ahmed, K. Z., Baratok, T. and Sagi, F. 1992. A modified method for rapid callus induction by utilization of endosperm metabolites in mature and immature seeds of bread wheat (Triticum aestivum L.) and durum wheat (Triticum durum L.). Cereal Res. Comm. 20: 81-86. 
Bahieldin, A., Fahmy, E. M., Gad El-Karim, GH, A., El-Domyati, F. M., Hassan, H. Z. and Salam, T. Z. 1994. Detection of molecular genetic markers for salt tolerance in wild wheats. Egypt. J. Genet. Cytol. 23: 95-105.

Barakat, M. N. and Abdel-Latif, T. H. 1995. Somatic embryogensis and plant regeneration in callus from mature and immature embryo culture of wheat. Alexandria J. Agr. Res. 40: 113-129.

Chowdhury, S. H., Kato, K., Yamamato, Y. and Hayashi, K. 1991. Varietal variation in plant regeneration capacity from immature embryo among common wheat cultivars. Jap. J. Bread. 41: 443-450.

Grant, V. 1971. Plant Speciation. Columbia University Press, New York.

Huzwara, Y. 1962. Karyotype analysis is some genera of Compositae VIII. Further studies on the chromosomes of Aster. Amer. J. Bot. 49: 116-119.

Karp, A. and Maddock, S. E. 1984. Chromosome variation in wheat plants regenerated from cultured immature embryos. Theor. Appl. Genet. 67: 249-255.

Kihara, H. 1944. The discovery of DD analyzer, one of the ancestors of common wheat (preliminary reports). Aric. Hort. 19: 889-890.

Levan, A., Fredga, K. and Sanders, A. A. 1965. Nomenclature for centromeric position on chromosomes. Hereditas. 52: 201-220.

Mohamad, A. S. 1993. Tissue culture variability in wheat germ-plasm: callus initiation and long-term plant regeneration and maintenance. Pakistan. J. Sci. Indust. Res. 36: 306-309.

Mohamed, A. B. 1990. Genetic analysis of the physiological basis of tolerance to environmental stresses in wheat by means of aneuploidy. Ph. D. Thesis, Ain Shams Univ.

Novák, F. J., Ohnouková, L. and Kubaláková, M. 1978. Cytogenetic studies of callus tissue of wheat (Triticum aestivum L.). Cereal Res. Common. 6: 135-147.

Okamoto, M. and Sears, E. R. 1962. Chromosomes involved in transiocations obtain from haploids of common wheat. Can. J. Genet. Cytol. 4: 24-30.

Ozgen, M., Turet, S., Ozgen, S. and Sancak, C. 1996. Callus induction and plant regeneration from immature and mature embryos of winter durum wheat genotypes. Plant Breed. 115: 455-458.

Rashed, M. A., Fahmy, E. M., Bahieldin, A. and Hasab-Alla, F. 1998. Genome-specific molecular markers in wheat and related species. International Congress on Molecular Genetics. Feb. 21-25 (1998). 1: 107-130.

—, El-Seoudy, A. A., Fahmy, E. M., Salam, T. Z., Abdel-Aziz, S. H. and Abdel-Bary, A. A. A. 2004. Molecular genetic markers for salt stress tolerance in wheat. Egypt. J. Genet. Cytol. 33: 163-183.

Romero-Zarco, C. R. 1986. A new method for estimating karyotype asymmetry. Taxon 35: 526-530.

Sesek, S. and Kondic, A. 1997. Use of callus culture in selection of wheat genotypes tolerant to high salt ( $\mathrm{NaCl})$ concentrations. Selekcja Lsemenastrav. 4: 55-59.

Sharma, A. 1990. Taxonomy as related to genetic diversity in plants. J. Ind. Bot. Soc. 69: 1-3.

Singh, R. J. 1986. Chromosomal variation in immature embryo derived calluses of barley (Hordeum vulgare L.). Theor. Appl. Genet. 72: 710-716.

- 1993. Plant Cytogenetics. CRC Press, Florida.

Stebbins, G. L. 1950. Variation and Evolution in Plants. Columbia University Press, New York.

— 1971. Chromosomal Evolution in Higher Plants. Addison-Wesley, Reading, M. A.

Sears, E. R. 1975. The Wheats and Their Relatives. In: King R. C., (ed) Handbook of Genetics. Plenum Press, city name pp. 59-91. 